\title{
FINITE ELEMENT ANALYSIS OF MODIFIED CONEBOLT UNDER STATIC AND DYNAMIC LOADINGS
}

\author{
Benjamin Nguyen, Ming Cai, Krishna Challagulla \\ Bharti School of Engineering \\ Laurentian University \\ Sudbury, Canada \\ bv_nguyen@laurentian.ca \\ mcai@laurentian.ca \\ kchallagulla@laurentian.ca
}

\begin{abstract}
Axisymmetric finite element models are developed to simulate static pull test and dynamic drop test of MCB33 (modified conebolt with full dedonding) using ABAQUS. Results from the numerical models are in reasonable agreement with the test results. A parametric study is performed considering various variables (i.e. friction, cone angle, material strength, etc.) to analyze the performance of MCB33. The results demonstrate that friction between the steel and resin, cone angle, and the Poisson's ratio of the resin affect the static and dynamic behaviors of the rockbolt. These parameters can be modified to improve the current design and enhance the overall performance of the rockbolt.
\end{abstract}

Keywords: finite element analysis; rockbolt; modified conebolt; static pull test; dyanmic drop test

\section{INTRODUCTION}

As depth of mining and underground construction increases, stress-induced rock fracturing is inevitable due to high in-situ stress and complex geological and geometrical conditions in underground hard rock mines. In some cases, rock can fail violently, leading to seismic events and rockbursts $[1,3,6,7$ and 8$]$.

Rockbursts can cause fatalities and injuries to workers, damage mine infrastructures and equipment, disrupt production, thus increase investment risk. To minimize the rockburst risk, design measures will be required. As an important line of defense, ground control support systems are used to prevent or minimize rockburst damage to excavation and enhance workplace safety.

In some deep hard rock mines, the modified conebolt (MCB) [2] are used for dynamic rock support. To further improve the performance of the $\mathrm{MCB}$, design modification and subsequent static and dynamic testing is required. However, laboratory and field-testing of a new product is time-consuming and costly. To complete one design modification, several iterations of prototype manufacturing and testing are required. Hence computer-aided product design and testing is required to reduce the product development cycle and cost.

\section{A. Modified conebolt}

The modified conebolt shown in Fig. 1 is a long slender steel bar (17.3 mm diameter) with a cone-shaped anchorage, resin mixing blade and a plastic sleeve on the shank to fully debond the bolt from the resin grout and apply all loads to the bolt to facilitate cone plough. As the cone ploughs through grout in a controlled fashion, the bolt absorbs energy. The MCB33 (modified conebolt with $33 \mathrm{~mm}$ borehole size) attributes mostly to cone resistance in resin without the frictional forces of the shank. As a result, the cone plough is more predictable.

Once a borehole (e.g. diameter $33 \mathrm{~mm}$ ) is drilled deep into the stable hard rock, resin packs are inserted. The MCB33 is then drilled into the borehole while the resin-mixing blade mixes the resin, thus the bolt is encapsulated with resin. The plastic sleeve on the shank fully debonds the shank from the resin. When the resin is cured in a few minutes, the MCB33 is ready to take load and deform. If a rockburst is significant and impose a large dynamic loading to the rock, the cone will plough through the resin and aid in dissipating energy. The act of cone ploughing creates displacement without significant yielding of the bolt.

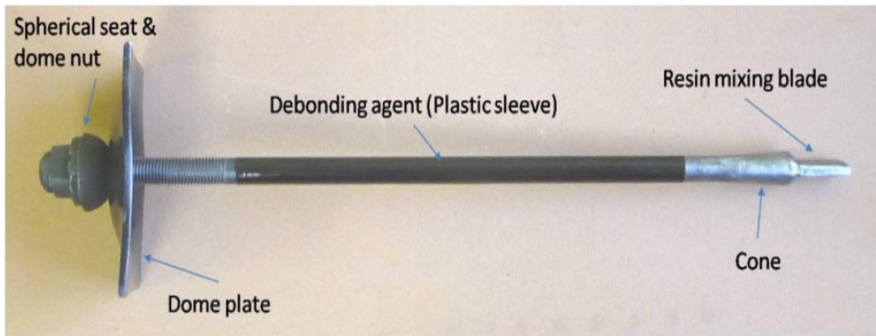

Figure 1. Schematic of a MCB33 [2]. 


\section{TESTING METHODS}

\section{A. Static pull test}

The static pull test is used to determine the loaddisplacement curve of a bolt. A hydraulic jack is used to apply a force on the end plate. The applied force on the bolt plate will deform the bolt and if load and displacement are measured, the load-displacement curve can be obtained.

\section{B. Dynamic drop test}

The dynamic drop test is used to evaluate energy absorbing capacities of rockbolts. A rockbolt is encapsulated in a thick wall steel pipe with the use of grout - resin or cement. A weight free falls onto the end plate to load the rockbolt dynamically at a pre-determined impact energy. Monitor systems are used to measure load and displacements at both ends of the rockbolt so that strains can be calculated. Fig. 2 shows the drop test facility at CANMET, Canada.

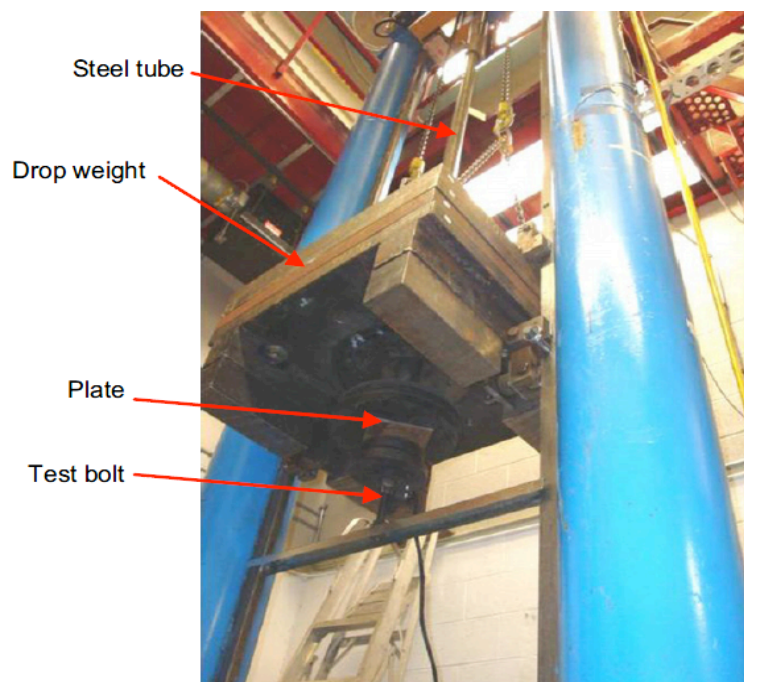

Figure 2. Drop test setup for MCB rockbolt testing at CANMET, Canada.

\section{MODELLING METHODOLOGY}

\section{A. Static pull test}

An axisymmetric finite element model of MCB33 (Fig. 3) is developed to simulate the in-situ pull test. The conebolt is fully encapsulated in resin in a $33 \mathrm{~mm}$ borehole in hard rock. Model dimensions of the rockbolt follow typical dimension of the modified conebolt for borehole sizes of $33 \mathrm{~mm}$, and the rock surrounding the borehole is large enough for using a fixed boundary condition. The axisymmetric model has four components: (a) modified conebolt for borehole size $33 \mathrm{~mm}$, (b) resin bonding the modified conebolt to the surround hard rock, (c) surrounding hard rock, and (d) interface between the bolt and the resin.

The following assumptions are considered to simplify the static pull test model:

- The rockbolt has no threads
- No head nut and plate for the rockbolt

- $\quad$ Rock-resin interface is assumed to be tied

- Friction interface is assumed for the bolt-resin interface.

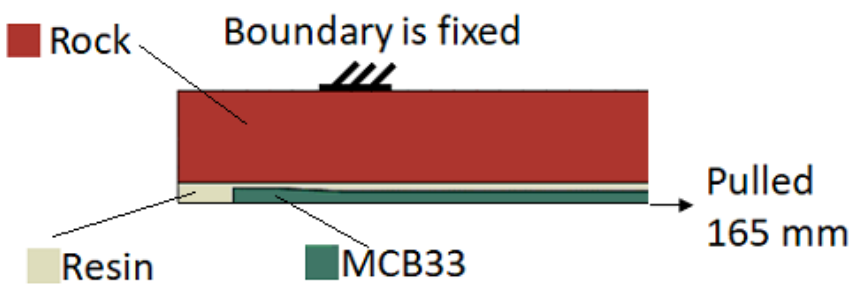

Figure 3. Schematic of the axisymmetric static pull test model (not to scale).

\section{B. Dynamic drop test}

An axisymmetric finite element model of the modified conebolt is developed to simulate the dynamic drop test. A conebolt is fully encapsulated in resin in a steel pipe with 33 $\mathrm{mm}$ inner diameter. The pipe wall is $13.5 \mathrm{~mm}$ thick. A drop weight around the pipe is dropped from $1.5 \mathrm{~m}$ height to impact the plate. The model has five components: (a) a modified conebolt for borehole size $33 \mathrm{~mm}$ with a plate, (b) resin bonding the modified conebolt and the pipe, (c) surrounding pipe, (d) drop weight, and (d) interface between the bolt and the resin.

The following assumptions are considered to simplify the dynamic drop test model:

- The rockbolt has no threads

- No head nut for the rockbolt

- Resin-pipe interface is assumed to be tied

- $\quad$ Friction interface is assumed for bolt-resin interface.

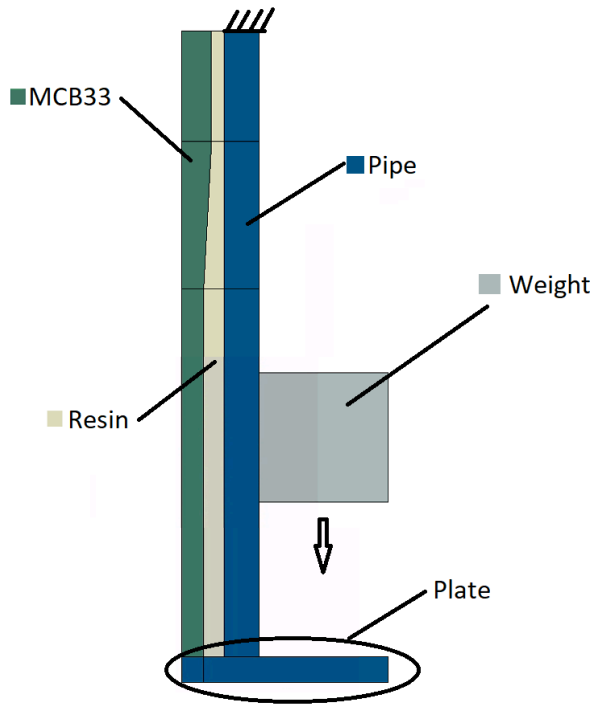

Figure 4. Schematic of the axisymmetric dynamic drop test model (not to scale). 


\section{Finite element model properties}

All finite element models developed in this study are analyzed using dynamic explicit analysis. Axisymmetric stress quad (CAX4R) element in ABAQUS is utilized to simulate the static pull test and the dynamic drop test. Because computational time is less for this type of analysis, a fine mesh with an aspect ratio between 1 and 1.5 is used.

As mentioned above the MCB has a debonded shank. The coefficient of friction affects the contact behaviors of the shank-to-resin interface and the cone-to-resin interface. We assume frictionless for the shank-to-resin interface due to perfect debonding, but the friction of the cone-to-resin interface is unknown thus a parametric study is needed to investigate the effect of the coefficient of friction of the coneto-resin interface on the performance of $\mathrm{MCB}$.

\section{Material properties}

For initial models the material properties are either measured through lab testing or obtained from available values in literature. The aim is to choose a property that best represents each component. The two main components of concerns are the encapsulate resin and the rockbolt. All other parts (e.g. rock, pipe, plate and weight) are simplified to isotropic elastic homogenous materials.

To represent the rockbolt, the model must be able to represent pre- and post-failure. The steel's (C1055) tensile and compressive behaviors are the same; thus the selection of an appropriate material model is based on elasticity, plasticity and ductile damage consideration. Experiments were conducted to determine the deformation behavior of the steel. The forcedisplacement curve obtained from the experiments was converted into true stress-true strain curve for input into ABAQUS.

The encapsulated resin is difficult to represent in the model because of the plastic softening behavior. Laboratory experiments were conducted to determine the Faslok resin behavior. It is found that the behavior of the resin can be captured using Concrete Damage Plasticity [5] model.

The simulation results are compared with the experimental results [2] to calibrate the parameters of the static pull test model. Once the final model of fully calibrated data best represents the static pull test from the field experiments, the parameters (i.e. resin material properties and coefficient of friction) are used in the dynamic drop test.

Parameters obtained from the static pull test are utilized for the initial dynamic drop test model with an impact energy of $16 \mathrm{~kJ}$. The results from the dynamic drop test model are compared with the experiment ones [2]. The finite element model is further calibrated to replicate the experimental results for all drop tests with an impact energy of $16 \mathrm{~kJ}$. Then those parameters are used to simulate the drop test with $26 \mathrm{~kJ}$ impact energy.

\section{INPUT DATA USED IN ANALYSIS}

Table 1 presents the material properties used for each part of the simulation model. Table 2 presents the coefficients of friction between different interfaces for the static and dynamic tests. Fig. 5 shows the converted nominal stress-nominal strain curve from laboratory testing of tensile samples of the rockbolt material (C1055). Faslok resin is used for the encapsulating a bolt in a borehole or a steel pipe (for dynamic drop test). The pipe, plate, and weight are simulated using a general steel property. The density of the drop weight is varied to obtain the desired weight for each drop test. The rock material is for the surround rock and the Young's modulus can be varied to consider soft and hard rocks.

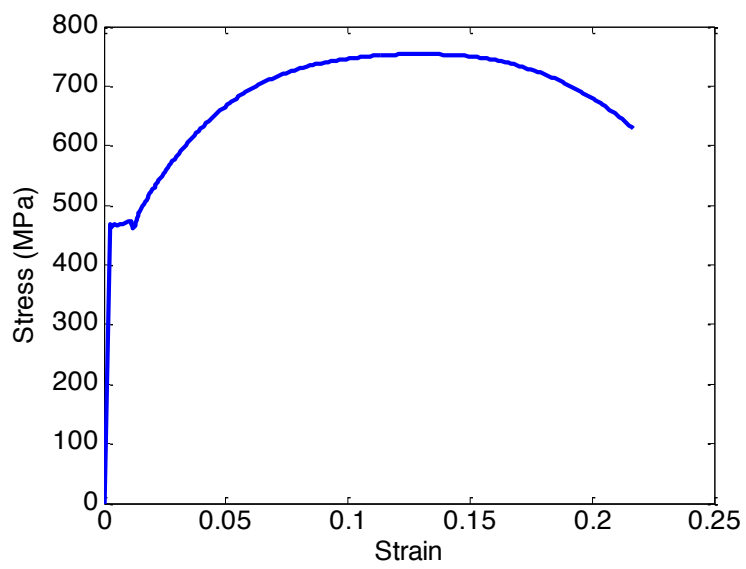

Figure 5. Stress-strain curve of C1055 steel obtained from lab test.

TABLE I. MATERIAL PROPERTIES FROM EXPERIMENTS AND LITERATURE [4]. * DEPENDING ON THE TEST AND THE GEOMETRY OF THE WEIGHT THE DENSITY IS CALCULATED TO GET 16 KJ AND 26 KJ IMPACT ENERGY

\begin{tabular}{|c|c|c|c|c|}
\hline \multirow{2}{*}{ Material } & \multicolumn{4}{|c|}{ Properties } \\
\cline { 2 - 5 } & $\begin{array}{c}\text { Young's } \\
\text { modulus } \\
(\mathbf{G P a})\end{array}$ & $\begin{array}{c}\text { Poisson's } \\
\text { ratio }\end{array}$ & $\begin{array}{c}\text { Density } \\
\left(\mathbf{K g} / \mathbf{m}^{3}\right)\end{array}$ & $\begin{array}{c}\text { Uniaxial } \\
\text { compressive } \\
\text { strength } \\
(\mathbf{M P a})\end{array}$ \\
\hline C1055 & 200 & 0.3 & 7500 & - \\
\hline $\begin{array}{c}\text { Faslok } \\
\text { resin }\end{array}$ & $10-30$ & $0.15-0.38$ & 2050 & 30 \\
\hline Steel & 210 & 0.3 & $*$ & - \\
\hline Rock & $5-50$ & 0.25 & $2440-2700$ & - \\
\hline
\end{tabular}

TABLE II. COEFFICIENTS OF FRICTION BETWEEN DIFFERENT INTERFACES

\begin{tabular}{|c|c|c|}
\hline \multirow{2}{*}{ Test } & \multicolumn{2}{|c|}{ Interface } \\
\cline { 2 - 3 } & Cone-resin & Shank-resin \\
\hline Static pull & $0.1-0.3$ & 0 \\
\hline Dynamic drop & $0.5-0.1$ & 0 \\
\hline
\end{tabular}




\section{SimUlation RESUltS}

\section{A. MCB33 static pull test simulation results}

With the axisymmetric models, preliminary design parameters are used to get a general idea of the trends and behavior of the MCB33 rockbolt under static loading. The model is further calibrated to give satisfactory results. Fig. 6 shows the stress in the y-direction (parallel to the bolt's long axis) when the conebolt is pulled $165 \mathrm{~mm}$. Fig. 7 presents the modeled load-displacement relation superimposed with the experiment results [2], showing a good agreement between the two.

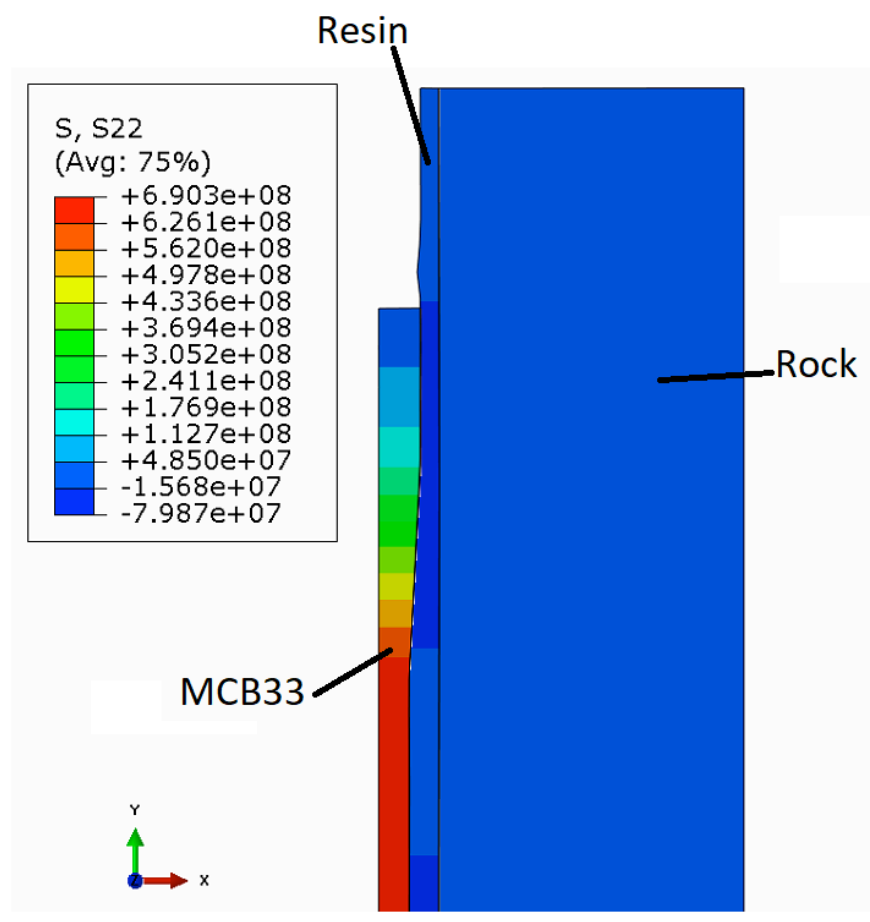

Figure 6. Top section of the MCB33 finite element model for the static pull test showing the stress $(\mathrm{Pa})$ distribution along the y-direction (S22).

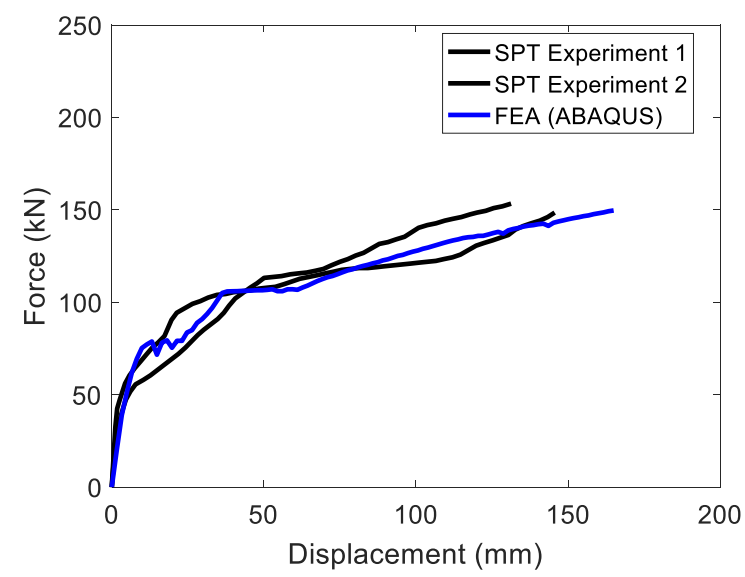

Figure 7. Static pull test (SPT) results [2] superimpossed with the results from numerical modeling (FEA).

\section{B. MCB33 dynamic drop test simulation results}

With the calibrated parameters using the static pull test results, dynamic drop test simulations were conducted. Fig. 8 shows the y-stress distribution at time $0.57 \mathrm{~s}$ from a $16 \mathrm{~kJ}$ drop test simulation. Figs. 9 and 10 show the plate displacements from the numerical simulations for $16 \mathrm{~kJ}$ and $26 \mathrm{~kJ}$ impact energy, respectively, superimposed with the experiment results [2]. It is seen that the numerical modeling captures the test results very well.

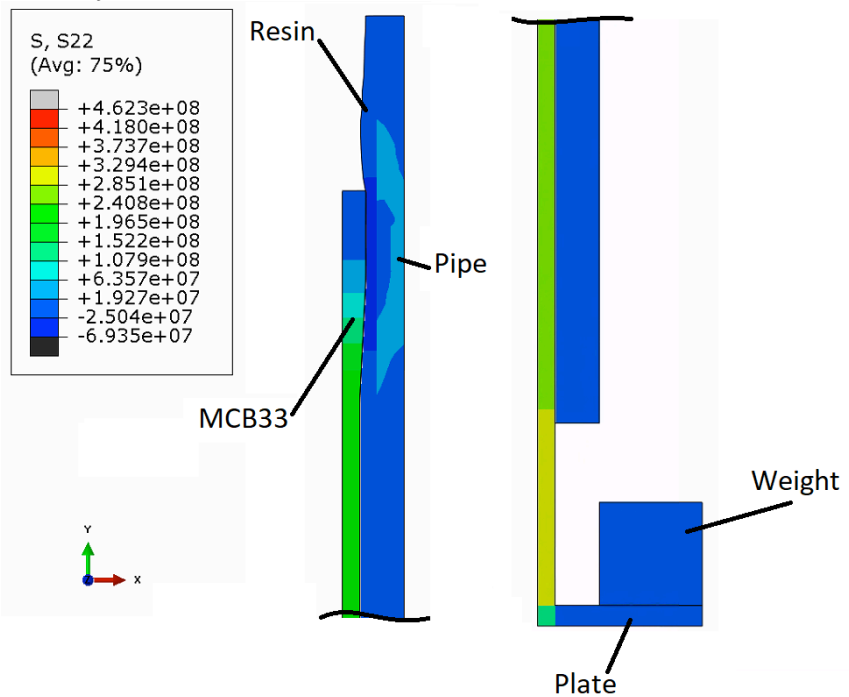

Figure 8. Top section (left side) and bottom section (right side) of the MCB33 dynamic drop test model showing stress (Pa) distribution in the ydirection (S22).

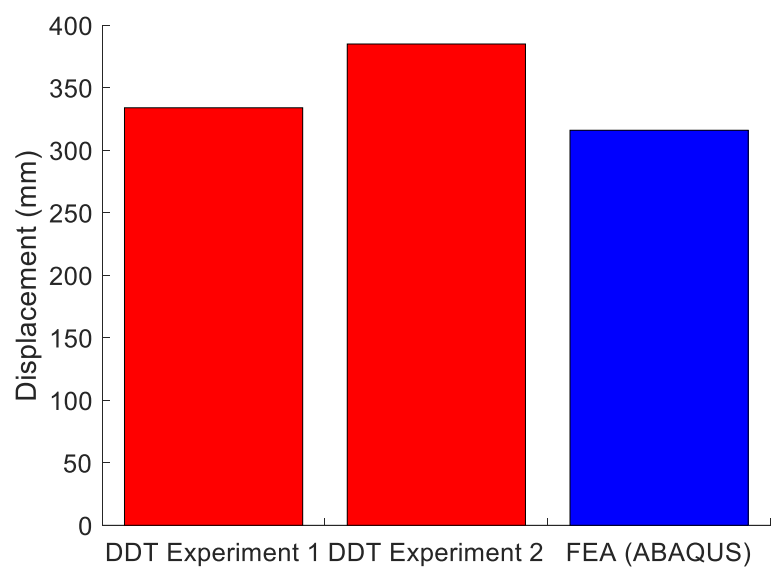

Figure 9. Dynamic drop test results for plate displacement at $16 \mathrm{~kJ}$ impact energy [2] superimposed with the numerical modeling results. 


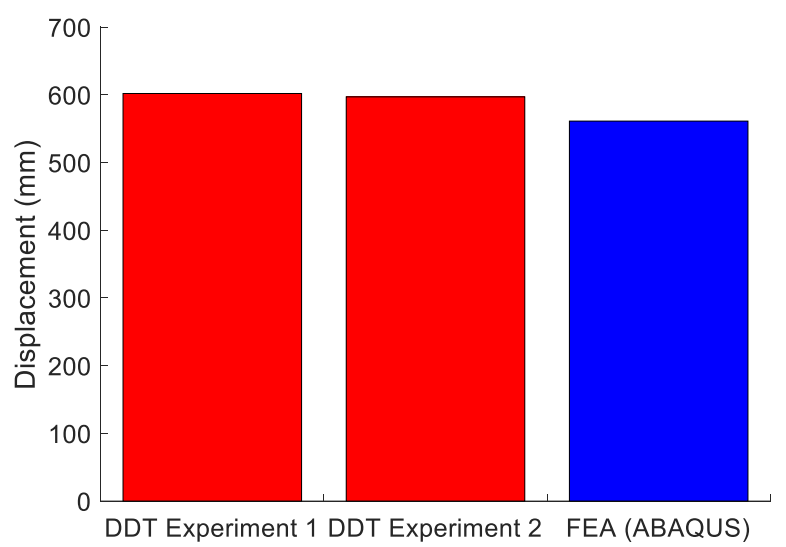

Figure 10. Dynamic drop test results for plate displacement at $26 \mathrm{~kJ}$ impact energy [2] superimposed with the numerical modeling results.

A further parametric study was conducted for both static and dynamic tests. The rockbolt material's strength and geometry, the resin material's strength and geometry, and the coefficient of friction between the bolt-resin interfaces are varied to study the performance of the bolt. It is seen from the static pull test and drop test simulation results that increasing the rockbolt material strength will increase performance of the MCB33. The resin material properties have a large influence on the performance of the MCB33. Higher Young's modulus of the resin grout can lead to less cone plough. Smaller coefficients between the bolt and the resin lead to more cone plough and increasing the cone angle reduces cone plough. Hence, it is possible to use numerical tools such as ABAQUS to calibrate available test results and refine design to optimize the performance of the MCB33 rockbolts.

\section{CONCLUSION}

Static and dynamic test results of MCB33 rockbolts have been simulated using an explicit FEM tool. The modeling results agree well with field and lab test results. Dynamic rock support is needed for mining in highly stressed ground to reduce rockburst damage risk and increase workplace safety. Further development of yielding rockbolts such as refinement of MCB33 and proofing other new support technologies can be assisted with the use of advanced numerical modeling to reduce product development cycle and cost.

\section{ACKNOLEDGEMENTS}

Financial supports from the Natural Sciences and Engineering Research Council (NSERC, CRDPJ 461108 - 13) of Canada and Mansour Mining Technologies Inc. for this work are gratefully acknowledged.

\section{REFERENCES}

[1] M. Cai and D. Champaigne, "The art of tock support in burst-trone ground," Keynote Leccture, In Proc. 7th International Symposium on Rockburst and Seismicity in Mines (RaSIM 7): Controlling Seismic
Hazard and Sustainable Development of Deep Mines, Dalian, China, pp: 33-46, 2009

[2] M. Cai and D. Champaigne, "Influence of bolt-grout bonding on MCB conebolt performance," International Journal of Rock Mechanics and Mining Sciences, vol. 49, pp. 165-175, 2012.

[3] M. Cai, "Principles of rock support in burst-prone ground," Tunnelling and Underground Space Technology, vol. 36, pp. 46-46

[4] L. Chen, G. Chen and G. Sheng, "Numerical modeling of rock bolts subject to dynamic loading," $46^{\text {th }}$ US Rock Mechanics/Geomechanics Symposium 2012, American Rock Mechanics Association (ARMA), pp. 277-283, 2012.

[5] U. Cicekli, G.Z. Voyiadjis and R.K. Abu al-rub, "A plasticity and anisotropic damage model for plain concrete," International Journal of Plasticity, vol. 23(10-11), pp. 1874-1900, 2012.

[6] P.K. Kaiser, D.R. Mccreath and D.D. Tannant, "Rockburst support handbook," Geomechanics Research Centre.

[7] P.K. Kaiser and M. Cai, "Design of rock support system under rockburst condition" Journal of Rock Mechanics and Geotechnical Engineering, vol. 4(3), pp. 215-227, 2012.

[8] D.D. Tannant, R.K. Brummer and X. Yi, "Rockbolt behaviour under dynamic loading: field tests and modelling," International journal of rock mechanics and mining sciences \& geomechanics abstracts, vol. 32(6), pp. 537-550, 1995. 